\title{
COMPOSIÇão FLORÍSTICA E DISTRIBUIÇão DE EPÍFITAS VASCULARES EM UM REMANESCENTE ALTERAdO DE FloRESTa EsTaCiONAL SEMIDECIDUAL no Paraná, Brasil
}

Greta Aline Dettke ${ }^{1,3}$, Andréa Cristina Orfrini² \& Maria Auxiliadora Milaneze-Gutierre ${ }^{2}$

\begin{abstract}
Resumo
(Composição florística e distribuição de epífitas vasculares em um remanescente alterado de Floresta Estacional Semidecidual no Paraná, Brasil) Estudos em várias regiões do globo têm demonstrado que a abundância, riqueza e estrutura das comunidades de epífitas vasculares, importantes elementos das florestas tropicais, mostram relevantes modificações de acordo com o grau de interferência sobre a estrutura das florestas. Este estudo teve como objetivo o levantamento e análise da distribuição da flora epifítica vascular do Parque do Ingá (Maringá, PR), verificando a existência de mudanças nesta sinúsia em zonas alteradas ao longo do fragmento estudado. Foram registradas 29 espécies de epífitas vasculares, representadas pelas famílias Bromeliaceae (7), Cactaceae (6), Polypodiaceae (4), Viscaceae (4), Orchidaceae (3), Araceae (2), Piperaceae (2) e Commelinaceae (1). A maioria das espécies são epífitas verdadeiras e as síndromes de dispersão predominantes são a endozoocoria e anemocoria. Em estudo quantitativo, foram amostradas 22 espécies, sendo as famílias mais importantes, quanto ao valor de importância epifítico, Polypodiaceae, Cactaceae e Bromeliaceae, ocupando preferencialmente o fuste alto e a copa. O índice de diversidade de Shannon para o Parque do Ingá foi de 1,106. Nas áreas de zoneamento do Parque há uma distribuição diferenciada das espécies epifíticas, de acordo com a umidade e oferta de luminosidade e nas áreas com maior impacto antrópico a riqueza de espécies foi menor, confirmando estudos anteriores em outras regiões de florestas tropicais.
\end{abstract}

Palavras-chave: flora, floresta tropical, síndrome de dispersão, fitossociologia.

\section{Abstract}

(Floristic composition and distribution of vascular epiphytes in an altered fragment of Seasonal Semideciduous Forest in Paraná State, Brazil) Studies in several areas of the world have been demonstrating that important elements of tropical forests like vascular epiphytes show relevant modifications according to the degree of interference on the structure of the forests. This study aims to rise and analyze the distribution of the vascular epiphytes of the Parque do Ingá (Maringá, PR) as well as to verify the existence of changes in this plant group in altered areas along the fragment. In qualitative study, 29 species of vascular epiphytes were registered, belonging to the families Bromeliaceae (7), Cactaceae (6), Polypodiaceae (4), Viscaceae (4), Orchidaceae (3), Araceae (2), Piperaceae (2) and Commelinaceae (1). Most of the species is holoepiphytes and the anemochory and endozoochory are predominant dispersion syndromes. In quantitative study, 22 species were showed. Considering the value of epiphytic importance, the most important families are Polypodiaceae, Cactaceae and Bromeliaceae. They occupy preferentially loud trunk and the top trees. The Shannon diversity index for the Parque do Ingá was of 1,106. In the zoning areas of the park there is a differentiated distribution of the epiphytic species, according to humidity and offer of light and in the areas with larger antropic impact the richness of species was low, confirming previous studies in other areas of tropical forests.

Key words: flora, tropical forest, dispersion syndromes, phytosociology.

\section{INTRODUÇÃo}

As epífitas vasculares compõem cerca de $10 \%$ de todas as plantas vasculares conhecidas, perfazendo em torno de 29.000 espécies (Gentry \& Dodson 1987a,b; Madison 1977). Representam importante contribuição à diversidade biológica das florestas tropicais, em termos de riqueza de espécies e biomassa (Gentry \& Dodson 1987a,b; Nadkarni 1985, 1992). São também importantes como fontes de recursos para os animais do dossel da floresta, seja como alimento (frutos, néctar e pólen),

Artigo recebido em 10/2007. Aceito para publicação em 11/2008.

${ }^{1}$ Programa de Pós-Graduação em Botânica, Universidade Federal do Rio Grande do Sul, Av. Bento Gonçalves 9500, Bloco

IV, Prédio 43433, Campus do Vale, Bairro Agronomia, 91501-970, Porto Alegre, RS, Brasil.

${ }^{2}$ Departamento de Biologia, Universidade Estadual de Maringá, Av. Colombo 5790, 87020-970 Maringá, PR, Brasil.

${ }^{3}$ Autor para correspondência: gretadet@yahoo.com.br 
água ou mesmo material para a construção de ninhos, possibilitando assim maior diversidade faunística (Benzing 1990). As epífitas também têm grande influência sobre a ciclagem de água e de nutrientes no interior das florestas (Nadkarni 1988).

Recentemente, as comunidades de epífitas vasculares têm sido utilizadas como bioindicadoras das mudanças climáticas, poluição e danos aos ecossistemas (Lugo \& Scatena 1992; Richter 1991). Estudos em várias regiões do globo têm demonstrado que a abundância, riqueza e estrutura das comunidades de epífitas vasculares mostram importantes modificações de acordo com o grau de interferência sobre a estrutura das florestas tropicais (Barthlott et al. 2001; Hietz 1997; Hietz-Seifert et al. 1996; Nkongmeneck et al. 2002; Turner et al. 1994). De modo geral, os autores observam a diminuição da abundância e riqueza de espécies epífitas em florestas secundárias em relação às florestas primárias, bem como a modificação na composição de espécies nestas áreas.

Nas últimas décadas vários estudos importantes sobre a sinúsia epifítica têm sido realizados nas Regiões Sudeste e Sul do Brasil, enfocando, além da composição específica, diversos aspectos ecológicos, tais como distribuição vertical, horizontal e ao longo de gradientes latitudinais, síndromes de polinização e dispersão e aspectos fitossociológicos, dentre outros (Breier 1999, 2005; Waechter 1992, 1998). Entretanto, poucos trabalhos existem para o grupo em áreas de Floresta Estacional Semidecidual (Breier 2005; Dislich \& Mantovani 1998; Pinto et al. 1995) e no estado do Paraná destacam-se os estudos de Cervi \& Borgo (2007), Borgo et al. (2002) e Tomazini (2003). Tais estudos, assim como a maioria dos trabalhos realizados no Brasil, restringem-se a uma abordagem florística e/ou fitossociológica e pouco discutem as conseqüências das alterações ambientais sobre a flora epifítica.

O município de Maringá, localizado no noroeste do Paraná, encontra-se sob domínio desta vegetação, mas atualmente poucas são as áreas com florestas nativas (menos de 0,5\%), devido à grande fronteira agrícola que se estabeleceu na região nas últimas seis décadas. Muitos são remanescentes alterados localizados no perímetro urbano municipal. Tal é o caso do Parque do Ingá, uma área de conservação. Em trabalhos anteriores, a área total deste parque foi subdividida em zonas de acordo com o grau de alteração, baseando-se principalmente na estrutura da comunidade arbóreo-arbustivo e histórico de regeneração da área (Prefeitura Municipal de Maringá 1994).

Em vista da importância das epífitas vasculares no contexto das florestas tropicais e da relevância da área de estudo como um dos últimos remanescentes de Floresta Estacional Semidecidual paranaense, este estudo teve como objetivos o levantamento e a análise da distribuição da flora epifítica vascular do Parque do Ingá, Maringá (PR). O intuito é avaliar se as áreas mais alteradas possuem número menor de espécies e composição comunitária diferenciada em relação às áreas mais preservadas, como apresentado nos estudos precedentes desta sinúsia.

\section{Materiais e Métodos Área de estudo}

O Parque do Ingá (Fig. 1) é uma Unidade de Conservação Municipal, destinada ao turismo, lazer e preservação ambiental, coberta com floresta nativa, embora bastante alterada pela ação antrópica. Encontra-se localizado no perímetro urbano do município de Maringá, com 47,3 ha de extensão e representa um dos últimos remanescentes regionais de Floresta Estacional Semidecidual (Prefeitura Municipal de Maringá 1994). O município de Maringá localiza-se a $23^{\circ} 25^{\prime} \mathrm{S}$ e $51^{\circ} 25^{\prime} \mathrm{W}$; apresenta precipitação média anual entre 1.500 e 1.600 $\mathrm{mm}$ e temperaturas médias anuais entre 20 $21^{\circ} \mathrm{C}$, com médias máximas de 27 a $28^{\circ} \mathrm{C}$ e mínimas entre 16 e $17^{\circ} \mathrm{C}$ (Anjos et al. 2001).

Para a efetivação deste estudo foram realizadas visitas quinzenais ao Parque do Ingá, entre os anos de 2003 e 2007, para a coleta de amostras de representantes epifíticos vasculares. Todo o material fértil coletado e herborizado foi incorporado ao Herbário da Universidade Estadual de Maringá (HUEM). 


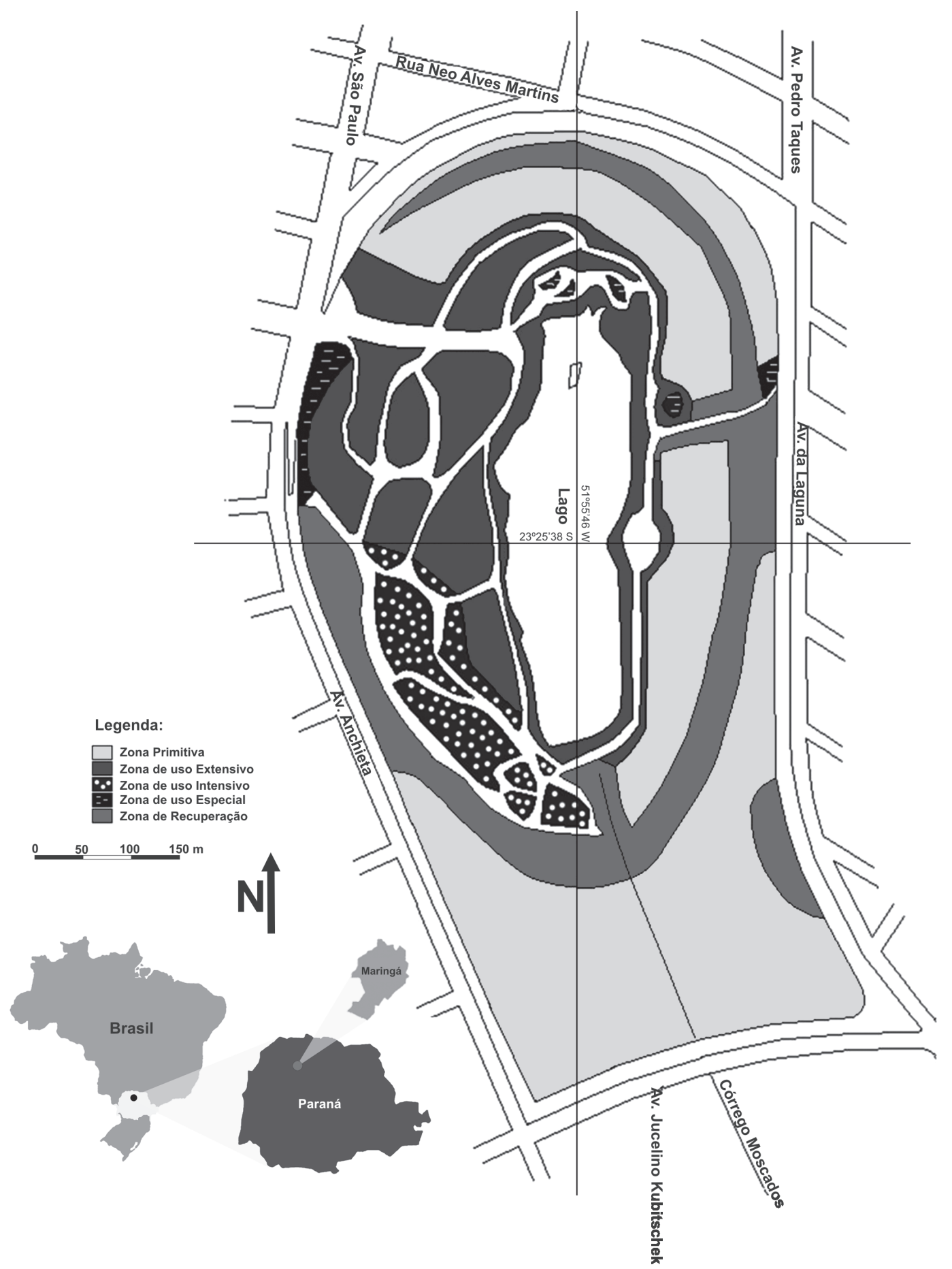

Figura 1 - Parque do Ingá, Maringá, Paraná, Brasil, e áreas do zoneamento (Modificado de: Prefeitura Municipal 1994). 
A identificação das famílias seguiu APGII (2003) para as angiospermas e de Tryon \& Tryon (1982) para as pteridófitas. Viscaceae, incluída por APGII (2003) em Santalaceae, foi tratada como família seguindo os recentes estudos de filogenia do grupo (Der \& Nickrent 2008). As espécies levantadas foram classificadas em categorias ecológicas, de acordo com a relação epífita-forófito baseado nas categorias definidas por Benzing (1990). Baseando-se nas observações de campo e nas informações bibliográficas (Madison 1977; Waechter 1992), também foram classificadas segundo a síndrome de dispersão de seus frutos, sementes ou esporos.

Dois tipos de estudo foram realizados: 1) estudo qualitativo, no qual foram registradas todas as espécies encontradas durante o período de estudo, 2) estudo quantitativo, onde foram escolhidas ao acaso, em campo, um total de 90 árvores com no mínimo $15 \mathrm{~cm}$ de diâmetro a 1,5 m de altura do solo (DAP), no mínimo $10 \mathrm{~m}$ distantes entre si. Para minimizar o efeito da preferência pela árvore, depois de selecionada a primeira árvore, foi realizado um sorteio da próxima direção a ser tomada, sendo incluída na análise a próxima árvore encontrada depois de percorridos, no mínimo, dez metros. Foram escolhidas 30 árvores em 'Zona Primitiva', 30 em 'Zona de Uso Extensivo' e 30 em 'Zona de Uso Intensivo', delimitadas de acordo com o plano de manejo do parque (Fig. 1). A 'Zona Primitiva' compreende áreas naturais pouco alteradas no contexto geral do parque, e que se destinam à manutenção do remanescente florestal; a 'Zona de Uso Extensivo' compreende áreas naturais alteradas que se caracterizam pela limitada circulação dos visitantes do parque e realização de atividades; e a 'Zona de Uso Intensivo' constitui-se basicamente por áreas alteradas, onde se concentram grande parte das atividades e serviços realizados no parque (Prefeitura Municipal de Maringá 1994).

Os forófitos foram divididos em três estratos para a análise da distribuição vertical das epífitas: fuste baixo (até 1,5 m do solo), fuste alto (de 1,5 $\mathrm{m}$ do solo até a base da copa) e copa, nos quais foram registradas todas as epífitas vasculares ocorrentes. Para cada espécie foi atribuída uma nota referente à sua respectiva abundância, modificado de Kersten \& Silva (2002), considerando-se, neste caso, o número aproximado de indivíduos ou módulos: 1) um ou poucos indivíduos isolados; 2) agrupamentos mais extensos ou diversos indivíduos isolados; 3) vários indivíduos.

Foram calculadas as freqüências absolutas de ocorrência nos estratos (FAr) e nos indivíduos forofíticos (FAi), enquanto o valor de importância epifítico (VIE) foi calculado com base nas notas atribuídas às epífitas. As fórmulas empregadas para estas análises foram as seguintes (Kersten \& Silva 2002): $\mathrm{FAr}=\left(\mathrm{nr}^{-n a^{-1}}\right) \cdot 100 ; \mathrm{FAi}=\left(\mathrm{ni}^{-n t^{-1}}\right) \cdot 100$; $\mathrm{VIE}=\left[\mathrm{vt} .\left(\mathrm{Óvt}_{\mathrm{vt}}\right)^{-1}\right] \cdot 100$, onde $\mathrm{nr}=$ número de regiões com ocorrência da espécie epifítica; na $=$ número total de regiões amostradas; $\mathrm{ni}=$ número de forófitos com a ocorrência da espécie; $\mathrm{nt}=$ número total de indivíduos; $\mathrm{vt}=$ somatória das notas obtidas pela espécie de acordo com sua respectiva abundância.

A partir dos dados do valor de importância epifítico, foi calculado o Índice de Diversidade de Shannon (H') (Margalef 1958) e Índice de Eqüidade de Pielou (J') (Odum 1988) para o Parque do Ingá (90 forófitos) e para cada Zona (30 forófitos cada).

Para a análise da similaridade florística entre as Zonas do Parque do Ingá e entre o Parque do Ingá e as demais áreas sob domínio de Floresta Estacional do Brasil, foi utilizado o Índice de Similaridade de Jaccard $(\mathrm{Sj})$. A análise de agrupamento (pelo método UPGMA, baseado no $\mathrm{Sj}$ ) foi realizada com o auxílio do software PAST (Hammer et al. 2001), considerando somente os grupos estudados em comum entre todos os autores e as espécies determinadas especificamente, com atualização das sinonímias.

\section{Resultados e Discussão}

No levantamento florístico foram registradas 29 espécies de epífitas vasculares, distribuídas em oito famílias (Tab. 1).

As famílias Bromeliaceae e Cactaceae possuem o maior número de representantes epífitos (24\% e $21 \%$, respectivamente), seguidas 
Tabela 1 - Lista de espécies epífitas na área de Floresta Estacional Semidecidual do Parque do Ingá, Maringá, Paraná, Brasil, e suas categorias ecológicas (EPA = epífitas acidentais; EPF = epífitas facultativas; $\mathrm{EPV}=$ epífitas verdadeiras; $\mathrm{HME}=$ hemiepífitas e HMP = hemiparasitas), síndromes de dispersão de diásporos (ANEM = anemocoria, $\mathrm{ENDO}=$ endozoocoria, $\mathrm{EXOZ}=$ exozoocoria) $\mathrm{e}$ número de registro do material de referência no HUEM.

\begin{tabular}{lccc}
\hline FAMÍLIA/ESPÉCIE & $\begin{array}{c}\text { Categoria } \\
\text { Ecológica }\end{array}$ & $\begin{array}{c}\text { Síndrome } \\
\text { de Dispersão }\end{array}$ & HUEM \\
\hline
\end{tabular}

\section{ARACEAE}

Philodendron bipinnatifidum Schott ex Endl

Syngonium affine Schott

$\begin{array}{lll}\text { HME } & \text { ENDO } & 12131 \\ \text { HME } & \text { ENDO } & 11963\end{array}$

\section{BROMELIACEAE}

Acanthostachys strobilacea (Schult.) Klotz.

Aechmea distichantha Lem.

EPV

Aechmea recurvata (Klotzsch) L.B. Sm.

Billbergia zebrina (Herb.) Lindl.

Tillandsia recurvata $(\mathrm{L}.) \mathrm{L}$.

Tillandsia pohliana $\mathrm{Mez}$

$\begin{array}{llc}\text { EPV } & \text { ENDO } & - \\ \text { EPF } & \text { ENDO } & 12110 \\ \text { EPV } & \text { ENDO } & - \\ \text { EPV } & \text { ENDO } & 11954 \\ \text { EPV } & \text { ANEM } & 11924 \\ \text { EPV } & \text { ANEM } & 11956 \\ \text { EPV } & \text { ANEM } & 11952\end{array}$

CACTACEAE

Epiphyllum phyllanthus (L.) Haw.

Lepismium cruciforme (Vell.) Miq.

Lepismium warmingianum (Schum.) Bart.

Rhipsalis baccifera (J. S. Mueller) Stearn

Rhipsalis cereuscula Haw.

Rhipsalis sulcata Web.

EPV

ENDO

11950

EPV

ENDO

11622

EPV

ENDO

11920

EPV

ENDO

11962

EPV

ENDO

11919

EPV

ENDO

11624

COMMELINACEAE

Tradescantia zebrina Heynh

EPA

EXOZ

11959

ORCHIDACEAE

Campylocentrum sp.

EPV

ANEM

EPV

ANEM

11964

Trichocentrum pumilum (Lindl.) M.W.Chase

EPV

ANEM

11958

\& N.H.Williams

PIPERACEAE

Peperomia catharinae Miq.

Peperomia circinnata Link.

EPV

EXOZ

EPV

EXOZ

POLYPODIACEAE

Microgramma squamulosa (Kaulf.) de la Sota

Microgramma vacciniifolia (Langsd. \& Fisch.) Copel.

EPV

ANEM

11953

EPV

ANEM

11921

Pleopeltis angusta Humb. \& Bonpl. ex Willd.

EPV

ANEM

11951

Polypodium polypodioides (L.) Watt

EPV

ANEM

11922

\section{VISCACEAE}

Phoradendron acinacifolium Mart.

Phoradendron linearifolium Eichl.

HMP

ENDO

11834

$\begin{array}{lll}\text { HMP } & \text { ENDO } & 11836\end{array}$

Phoradendron piperoides (H. B. K.) Nutt.

HMP

ENDO

11835

Phoradendron rubrum (L.) Griseb.

HMP

ENDO 
por Polypodiaceae e Viscaceae (14\% cada), Orchidaceae (10\%), Araceae e Piperaceae (7\% cada) e Commelinaceae (3\%).

De acordo com Dislish (1996), na maioria das floras epifíticas conhecidas nos trópicos americanos, Orchidaceae é a família mais importante, seguida por Pteridophyta, Bromeliaceae e Araceae, sendo que este padrão é independente da pluviosidade. Na região da Planície Costeira do Rio Grande do Sul, por exemplo, Waechter (1992) encontrou cerca de $50 \%$ das espécies pertencentes à Orchidaceae, de um total de 250 espécies levantadas. Em adição, em áreas preservadas sob o domínio de Floresta Estacional Semidecidual, Orchidaceae também é citada como a família mais rica em número de espécies (Borgo et al. 2002; Breier 2005; Cervi \& Borgo 2007; Dislich \& Mantovani 1998; Tomazini 2003). No entanto, este padrão não foi observado na composição florística de epífitas vasculares do Parque do Ingá, sendo mais numerosas as famílias Bromeliaceae e Cactaceae, que juntas representam cerca de $50 \%$ das espécies amostradas. Orchidaceae foi representada por apenas três espécies (10\%).

Isso provavelmente denota o impacto antrópico ao qual este fragmento florestal foi submetido nas últimas seis décadas, tanto por torná-lo isolado das demais áreas de floresta nativa, impedindo assim a recolonização por espécies nativas, como pela retirada excessiva de representantes de Orchidaceae, por seu grande valor ornamental. Outro fator a ser considerado, decorrente da fragmentação da área, é a mudança dos níveis de umidade, fator este que tem impacto direto sobre a sobrevivência e colonização de espécies de orquídeas epífitas (Benzing 1990; Partomihardjo 2003). Pinto et al. (1995) registraram a ausência desta família em um pequeno fragmento de floresta altamente alterado no município de Jaboticabal (SP), onde possivelmente os mesmos fatores citados para o Parque do Ingá estejam atuando.

Viscaceae é pouco citada em levantamentos de epífitas vasculares devido ao modo de vida hemiparasítico de seus representantes (Aguiar et al. 1981; Breier 2005). No Parque do Ingá esta família esteve representada por quatro espécies, todas pertencentes ao gênero Phoradendron.

Além das espécies citadas na Tabela 1, ocorreram outras três espécies de epífitas vasculares na área estudada: Selenicereus anthonyanus (Alexander) D.R. Hunt. e Hylocereus undatus (Haw.) Britton \& Rose (Cactaceae) e Dendrobium nobile Lindl. (Orchidaceae). Todas são exóticas e introduzidas nas áreas intensamente visitadas do Parque do Ingá, não sendo encontradas em outros locais. Por outro lado, as espécies também exóticas, consideradas neste estudo, Syngonium affine e Tradescantia zebrina são encontradas em todas as Zonas do Parque, inclusive nas mais preservadas, indicando-as como colonizadoras e possivelmente espécies adventícias.

De acordo com as categorias ecológicas propostas por Benzing (1990), baseadas na relação com o forófito, a maioria das espécies observadas constitui-se de epífitas verdadeiras, representadas por 21 espécies (73\%). As hemiparasitas foram representadas por quatro espécies (14\%), as hemiepífitas por duas espécies (7\%), e as epífitas facultativas e acidentais por uma espécie cada (3\%).

A participação das categorias ecológicas de epífitos vasculares é muito semelhante às encontradas em outros levantamentos, com predominância de epífitas verdadeiras sobre as demais categorias (Aguiar et al. 1981; Borgo et al. 2002; Borgo \& Silva 2003; Breier 1999, 2005; Cervi et al. 1988; Cervi \& Borgo 2007; Dislich \& Mantovani 1998; Dittrich et al. 1999; Giongo \& Waechter 2004; Gonçalves \& Waechter 2003; Kersten \& Silva 2001, 2002; Rogalski \& Zanin 2003; Tomazini 2003; Waechter 1986, 1992, 1998).

A síndrome de dispersão de diásporos predominante é a endozoocoria, presente em 16 espécies (56\%). Dez espécies (34\%) apresentam-se anemocóricas e três espécies (10\%) exozoocóricas. Esta proporção na síndrome de dispersão dos diásporos difere da encontrada em estudos da flora epifítica em áreas mais preservadas, onde a anemocoria 
Tabela 2 - Lista de espécies epífitas na área de Floresta Estacional Semidecidual do Parque do Ingá, Maringá, Paraná, Brasil, classificadas segundo o valor de importância epifítica (ne = número absoluto de ocorrência de estratos, $\mathrm{FAr}=$ Freqüência absoluta nos estratos, ni = número absoluto de ocorrência nos indivíduos forofíticos, FAi $=$ Frequiência absoluta nos indivíduos forofíticos, VIE $=$ valor de importância epifítico).

\begin{tabular}{llllll}
\hline Espécie & ne & FAr $(\boldsymbol{\%})$ & ni & FAi $(\%)$ & VIE \\
\hline Pleopeltis angusta & 99 & 36,67 & 59 & 65,56 & 19,43 \\
Polypodium polypodioides & 55 & 20,37 & 36 & 40,00 & 11,05 \\
Tillandsia tricholepis & 58 & 21,48 & 35 & 38,89 & 10,87 \\
Rhipsalis cereuscula & 41 & 15,19 & 27 & 30,00 & 9,09 \\
Lepismium cruciforme & 34 & 12,59 & 26 & 28,89 & 7,31 \\
Tillandsia recurvata & 49 & 18,15 & 24 & 26,67 & 7,31 \\
Lepismium warmingianum & 28 & 10,37 & 21 & 23,33 & 6,95 \\
Epiphyllum phyllanthus & 29 & 10,74 & 26 & 28,89 & 6,77 \\
Microgramma squamulosa & 23 & 8,52 & 18 & 20,00 & 6,06 \\
Tillandsia pohliana & 29 & 10,74 & 21 & 23,33 & 5,53 \\
Phoradendron linearifolium & 4 & 1,48 & 4 & 4,44 & 1,78 \\
Miltonia flavescens & 5 & 1,85 & 4 & 4,44 & 1,43 \\
Aechmea recurvata & 4 & 1,48 & 4 & 4,44 & 1,25 \\
Aechmea distichantha & 5 & 1,85 & 4 & 4,44 & 1,07 \\
Philodendron bipinnatifidum & 4 & 1,48 & 3 & 3,33 & 1,07 \\
Rhipsalis baccifera & 3 & 1,11 & 3 & 3,33 & 0,89 \\
Peperomia circinnata & 3 & 1,11 & 2 & 2,22 & 0,53 \\
Syngonium affine & 2 & 0,74 & 1 & 1,11 & 0,53 \\
Microgramma vacciniifolia & 2 & 0,74 & 1 & 1,11 & 0,36 \\
Tradescantia zebrina & 2 & 0,74 & 1 & 1,11 & 0,36 \\
Bilbergia zebrina & 1 & 0,37 & 1 & 1,11 & 0,18 \\
Trichocentrum pumilum & 1 & 0,37 & 1 & 1,11 & 0,18 \\
\hline
\end{tabular}

predomina sobre as demais categorias, devido principalmente à alta representatividade de Orchidaceae (Tomazini 2003; Waechter 1992). Por outro lado, a presença de espécies epífitas com dispersão endozoocórica torna-se relevante na área de estudo, dado que muitas espécies animais dependem deste recurso alimentar ao longo do ano, tornando esta área uma mantenedora da diversidade faunística em ambiente urbano e também possibilitando a dispersão destas espécies de epífitas para outros fragmentos existentes na cidade.

\section{Estudo Quantitativo}

Foram encontradas 22 espécies de epífitas vasculares, distribuídas em oito famílias, representando $76 \%$ das espécies listadas no estudo qualitativo (Tab. 2). Num total de 90 árvores amostradas, 10 delas (11\%) não apresentaram epífitas. A média de DAP das árvores analisadas foi de $42,3 \mathrm{~cm}$, com diâmetros variando entre 18 e $95 \mathrm{~cm}$. O índice de diversidade de Shannon estimado para a amostra foi de $\mathrm{H}^{\prime}=1,106$ e a eqüidade $\mathrm{J}^{\prime}=0,824$. $\mathrm{O}$ índice de diversidade encontrado para a área de estudo é bastante baixo 


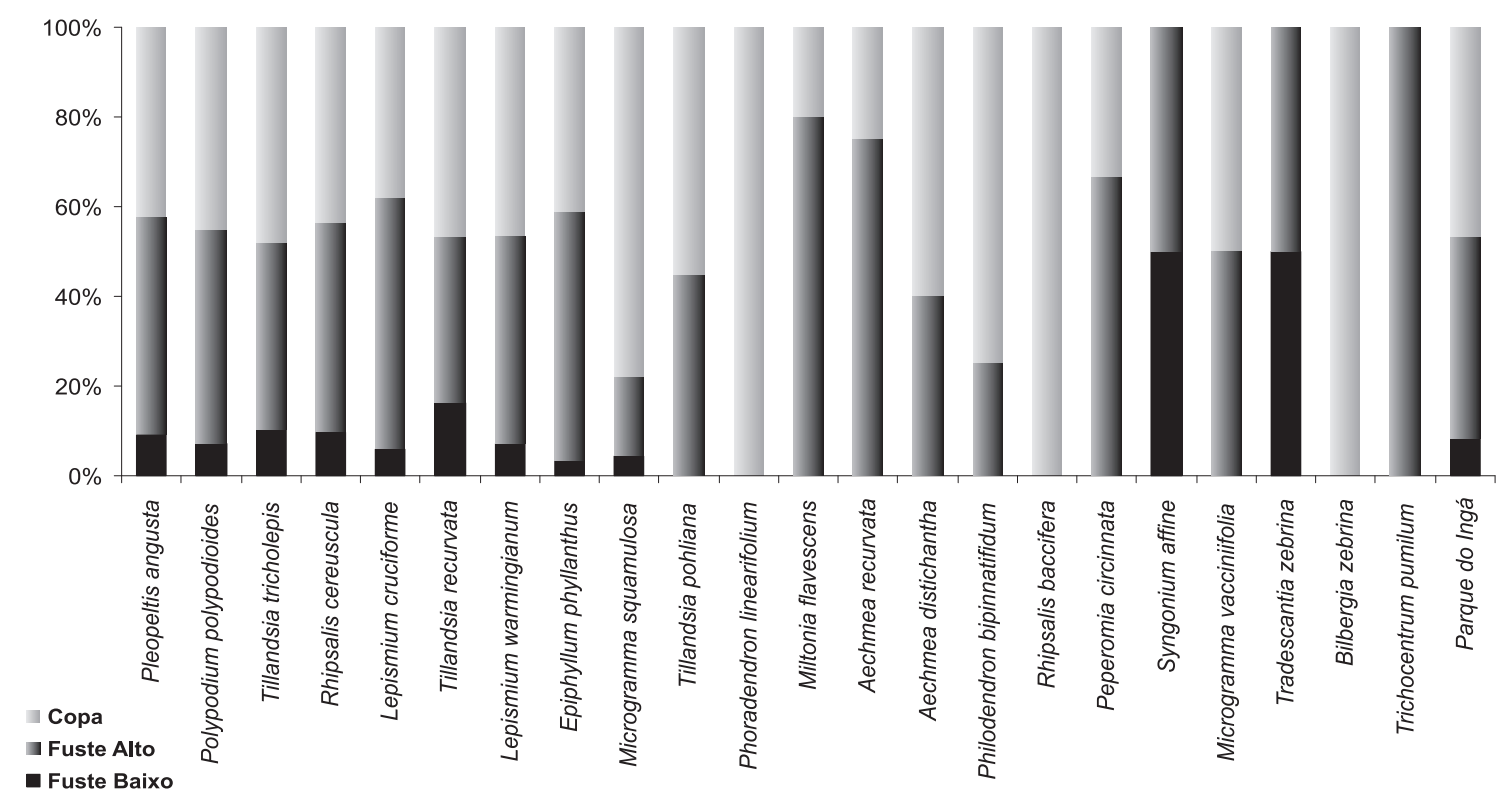

Figura 2 - Epífitas vasculares observadas no Estudo Quantitativo na área de Floresta Estacional Semidecidual do Parque do Ingá, município de Maringá, Paraná, Brasil, de acordo com sua distribuição vertical no forófito.

em relação aos demais estudos desta sinúsia no sul do Brasil (Waechter 1992, 1998; Kerten \& Silva 2001, 2002). Entretanto, deve ser ressaltado que em tais estudos foram utilizados diferentes métodos para a obtenção do seu valor.

Pleopeltis angusta destacou-se como a espécie mais importante, com valor de importância epifítica (VIE) de 19,43 (Tab. 2). Esta espécie ocorreu em $66 \%$ dos forófitos e $37 \%$ dos estratos, sendo que sua presença no fuste alto e copa foi de $48 \mathrm{e} 42 \%$, respectivamente (Fig. 2). Kesten \& Silva (2002) encontraram esta espécie como segunda mais importante em área de floresta ombrófila mista aluvial do rio Barigüi (PR).

A segunda espécie mais importante neste estudo é Polypodium polypodioides com VIE igual a 11,05 , ocorrendo em $40 \%$ do forófitos e 20\% dos estratos. Esta espécie foi predominante no fuste alto (47\%) e copa (45\%) (Fig. 2).

A terceira espécie com o VIE acima de dez foi Tillandsia tricholepis (VIE=10,87), amostrada em 39\% dos indivíduos forofíticos e em $21 \%$ dos estratos, sendo sua presença de $49 \%$ na copa e $41 \%$ no fuste alto. Com VIE igual a 9,09, Rhipsalis cereuscula foi amostrado em $30 \%$ dos forófitos e $15 \%$ dos estratos. Sua presença foi de $46 \%$ no fuste alto e $44 \%$ na copa.

Lepismium cruciforme e Tillandsia recurvata obtiveram o mesmo VIE $(7,31)$, a primeira ocorrendo em $29 \%$ dos estratos e $13 \%$ dos forófitos, a segunda em $27 \%$ dos estratos e $18 \%$ dos forófitos. Respectivamente, tiveram abundância de 56 e $37 \%$ no fuste alto e 38 e $47 \%$ na copa, como demonstrado na Figura 2.

Lepismium warmingianum, Epiphyllum phyllanthus, Microgramma squamulosa e Tillandsia pohliana obtiveram VIE próximos (entre 5,53 e 6,95), sendo mais abundantes tanto no fuste alto quanto na copa dos forófitos (Fig. 2).

O restante das espécies de epífitas vasculares amostradas obteve VIE inferior a 1,8, e em conjunto representaram 9,63 do VIE, sendo suas frequiências e distribuição vertical variável, conforme apresentado na Tabela 2 e Figura 2, respectivamente.

As famílias mais importantes foram Polypodiaceae, Cactaceae e Bromeliaceae, que juntas compõe aproximadamente $94 \%$ do VIE da amostra, sendo seus respectivos valores de importância epifítica igual a 36,90; 31,02 e 
26,20. A dominância destas famílias deve-se principalmente às características adaptativas de suas espécies. Tryon (1970) propôs que, aliada à grande plasticidade fenotípica de seus esporos, a ampla distribuição de algumas espécies de Polypodiaceae relaciona-se com a facilidade de dispersão anemocórica de tais estruturas reprodutivas, podendo ser levados à longas distâncias; além de permanecerem viáveis por um período de tempo considerável. Tais características também foram observadas nas Bromeliaceae, principalmente nas espécies de Tillandsia, cujas sementes também são anemocóricas, podendo atingir longas distâncias da planta mãe, o que certamente explica sua ampla dispersão no Parque do Ingá.

Quanto à distribuição vertical, em média, 47\% das espécies de epífitas ocorreram na copa dos forófitos, seguidos de $45 \%$ no fuste alto e $8 \%$ no fuste baixo, como observado na Figura 2.

O número de espécies epífitas por forófito variou de zero a 11 no Parque do Ingá, com uma média de 3,4 epífitas por forófito. Entre as áreas do zoneamento do Parque, a média de epífitas por forófito foi de 3,0 na Zona Primitiva (ZP), 3,6 na Zona de Uso Extensivo (ZUE) e de 4,0 na Zona de Uso Intensivo (ZUI).

As áreas de zoneamento do Parque do Ingá apresentam similaridades superiores a $55 \%$ entre si, sendo de $64 \%$ entre a ZUE e ZP, $61 \%$ entre ZUE e ZUI e de 55\% entre a ZUI e a ZP.

Algumas espécies são restrita à apenas uma das áreas, enquanto outras, geralmente as mais abundantes, são encontradas em todas as áreas, como as três espécies de Polypodiaceae encontradas, Cactaceae (Epiphyllum phyllanthus, Lepismium cruciforme, L. warmingianum e Rhipsalis cereuscula) e Bromeliaceae (Tillandsia pohliana, $T$. recurvata e T. tricholepis) (Tab. 3). No entanto, essas áreas diferem quanto ao valor de importância epifítico de suas espécies, como observado na Tabela 4.

Em vista disso, percebe-se uma zonação das espécies de epífitas vasculares do Parque do Ingá, determinada pelas exigências morfofisiológicas das espécies e nível de distúrbio antrópico.
$\mathrm{Na}$ Zona de Uso Intensivo há maior abundância de espécies heliófitas, como por exemplo, as três espécies de Tillandsia que tiveram maior VIE nesta área, provavelmente devido à maior luminosidade promovida pela rarefação de espécies arbóreas nesta área e pela maior facilidade de dispersão de suas sementes plumosas em ambientes abertos. Assim, estas espécies poderiam ser utilizadas como bioindicadores de fragmentos alterados, tal como sugerido por Barthlott et al. (2001) para florestas montanas dos Andes venezuelanos. Os autores encontraram, em ambientes alterados, maior diversidade e abundância de bromélias epífitas (todas da subfamília Tillandsioideae) que nas florestas primárias.

NaZona Primitiva e Zona de Uso Extensivo a mata ainda conserva características originais da Floresta Estacional Semidecidual, o que proporciona um dossel fechado, que impede a entrada de alta luminosidade e favorece uma umidade maior, beneficiando espécies epífitas tolerantes ou exigentes de baixas taxas de luminosidade, como algumas espécies de Polypodiaceae (Microgramma squamulosa), de Cactaceae (L. cruciforme, L. warmingianum, $R$. cereuscula, E. phyllanthus) e Araceae. Barthlott et al. (2001) destacam a grande abundância de espécies de pteridófitas e orquídeas em florestas primárias, cuja presença em áreas secundárias pode reduzir-se em até $60 \%$, no caso de Orchidaceae. As espécies de Polypodiaceae, encontradas neste estudo, Pleopeltis angusta e Polypodium polypodioides, seriam uma exceção à regra, pois apresentam importância relativamente alta nas três zonas; tal evento deve-se, possivelmente, ao fato destas espécies serem poiquiloídricas e passíveis de competição nos ambientes onde a umidade relativa do ar é baixa, como na Zona de Uso Intensivo.

Essas três áreas também diferem quanto à riqueza de espécies $(\mathrm{S})$ : 12 na ZUI, 17 na ZUE e 19 espécies na ZP. O índice de Shanonn foi maior na ZP e ZUE (1,111 e 1,047, respectivamente) e menor na ZUI $(0,963)$, nesta porém, a eqüidade foi maior $(0,892)$ quando comparada com as demais áreas $(0,869$ 
Tabela 3 - Valor de importância epifítico (VIE) de espécies encontradas no Estudo Quantitativo na área de Floresta Estacional Semidecidual do Parque do Ingá, Maringá, Paraná, Brasil, distribuídas conforme zoneamento $(\mathrm{ZUI}=$ Zona de Uso Intensivo, ZUE = Zona de Uso Extensivo, ZP = Zona Primitiva).

\begin{tabular}{llll}
\hline & & VIE $(\boldsymbol{\%})$ & ZP \\
\hline Espécies & ZUI & ZUE & 21,51 \\
\hline Pleopeltis angusta & 20,10 & 16,76 & 8,72 \\
Polypodium polypodioides & 10,78 & 13,51 & 6,98 \\
Tillandsia tricholepis & 18,14 & 6,49 & 10,47 \\
Rhipsalis cereuscula & 3,92 & 13,51 & 8,14 \\
Lepismium cruciforme & 5,39 & 8,65 & 1,74 \\
Tillandsia recurvata & 14,71 & 4,32 & 5,81 \\
Lepismium warmingianum & 2,45 & 12,97 & 8,14 \\
Epiphyllum phyllanthus & 3,92 & 8,65 & 9,30 \\
Microgramma squamulosa & 4,41 & 4,86 & 1,74 \\
Tillandsia pohliana & 10,78 & 3,24 & 0,00 \\
Phoradendron linearifolium & 4,41 & 0,54 & 4,65 \\
Miltonia flavescens & 0,00 & 0,00 & 2,91 \\
Aechmea recurvata & 0,00 & 1,08 & 2,91 \\
Aechmea distichantha & 0,00 & 0,54 & 1,16 \\
Philodendron bipinnatifidum & 0,00 & 2,16 & 1,16 \\
Rhipsalis baccifera & 0,00 & 1,62 & 0,58 \\
Peperomia circinnata & 0,98 & 0,00 & 1,74 \\
Syngonium affine & 0,00 & 0,00 & 1,16 \\
Microgramma vacciniifolia & 0,00 & 0,00 & 1,16 \\
Tradescantia zebrina & 0,00 & 0,00 & 0,00 \\
Bilbergia zebrina & 0,00 & 0,54 & 0,00 \\
Trichocentrum pumilum & 0,00 & 0,54 & \\
\hline
\end{tabular}

Tabela 4 - Sumário da abundância e riqueza de espécies do Parque do Ingá, Maringá, Paraná, Brasil ( $\mathrm{S}$ = riqueza de espécies, H' = Índice de Shannon, J' = Eqüidade de Pielou).

\begin{tabular}{lcccc}
\hline & $\begin{array}{c}\text { Zona de } \\
\text { Uso Intensivo }\end{array}$ & $\begin{array}{c}\text { Zona de } \\
\text { Uso Extensivo }\end{array}$ & $\begin{array}{c}\text { Zona } \\
\text { Primitiva }\end{array}$ & $\begin{array}{c}\text { Parque } \\
\text { do Ingá }\end{array}$ \\
\hline S & 12 & 17 & 19 & 22 \\
H' & 0,963 & 1,047 & 1,111 & 1,106 \\
J' & 0,892 & 0,851 & 0,869 & 0,824 \\
\hline
\end{tabular}


e 0,851 , respectivamente) (Tab. 4). Este fato é similar ao encontrado em estudos anteriores em outras áreas de florestas tropicais americanas, especialmente o estudo de Barthlott et al. (2001), onde os autores verificaram o declínio de espécies epífitas de acordo com o grau de distúrbio de uma floresta secundária, com 65 espécies nas áreas mais preservadas e apenas sete espécies em áreas altamente alteradas. Vale ressaltar, entretanto, que os autores citados utilizaram uma área maior de estudo (aproximadamente $120 \mathrm{ha}$ ) em relação ao presente estudo (47,3 ha) e diferente método de levantamento da flora. Os autores atribuem a menor diversidade e abundância de epífitas vasculares em áreas alteradas à perda da complexidade estrutural das florestas primárias, no que diz respeito a abundância de microclimas ao longo dos estratos dos forófitos e à perda de forófitos de grande porte que sustentam grande quantidade de espécies.

Os ambientes perturbados são mais secos e ensolarados que o ambiente original, restringindo a colonização da maioria das espécies epífitas, altamente dependente da alta saturação de vapor d'água, favorecendo espécies heliófitas (Barthlott et al. 2001; Hiertz 1997). Por outro lado, é conhecido o fato de que muitas espécies epífitas têm crescimento lento, principalmente espécies de Orchidaceae, cujo período pode atingir até 30 anos (Hietz 1997; Zotz 1995), tornando a colonização das áreas alteradas um processo extremamente lento.

Em relação à riqueza de espécies, a área estudada apresenta um número baixo de espécies, principalmente se comparada com a riqueza de regiões sob domínio da Floresta Atlântica, Floresta Ombrófila Mista e regiões costeiras do Brasil (Borgo \& Silva 2003; Breier 1999, 2005; Cervi et al. 1988; Dittrich et al. 1999; Giongo \& Waechter 2004; Gonçalves \& Waechter 2003; Kersten \& Silva 2001, 2002; Waechter 1986, 1992, 1998), todas com níveis de pluviosidade e umidade relativamente maiores que a área estudada. Ressalta-se aqui também que a região de Maringá, área deste estudo, apresenta uma estação seca definida, entre os meses de maio e julho (Anjos et al.
2001). Bigarella \& Mazuchowski (1985) já haviam afirmado que a baixa umidade relativa do ar na região noroeste do Paraná inibe uma maior ocorrência de epífitos, devido à elevada evapotranspiração, limitando a sobrevivência nos períodos de precipitação deficiente. Este fato é endossado por Tomazini (2003) para a vegetação epifítica do Alto Rio Paraná, embora as áreas amostradas pela autora possam ter influência, principalmente de umidade, do rio Paraná.

A área do Parque do Ingá apresentou maior similaridade florística (aproximadamente $34 \%$ ) com área remanescente situada na Estação Ecológica Caetetus, no município de Gália (SP) (Breier 2005) e com as áreas do Alto Rio Paraná (Tomazini 2003) e Jaboticabal (SP) (Pinto et al. 2005) (Fig. 3). As áreas situadas em Marcelino Ramos (Rogalski \& Zanin 2003), PEVR Fênix (Borgo et al. 2002) e Parque Nacional do Iguaçu (Cervi \& Borgo 2007) formam um grupo onde predominam as maiores umidades relativas, que provavelmente

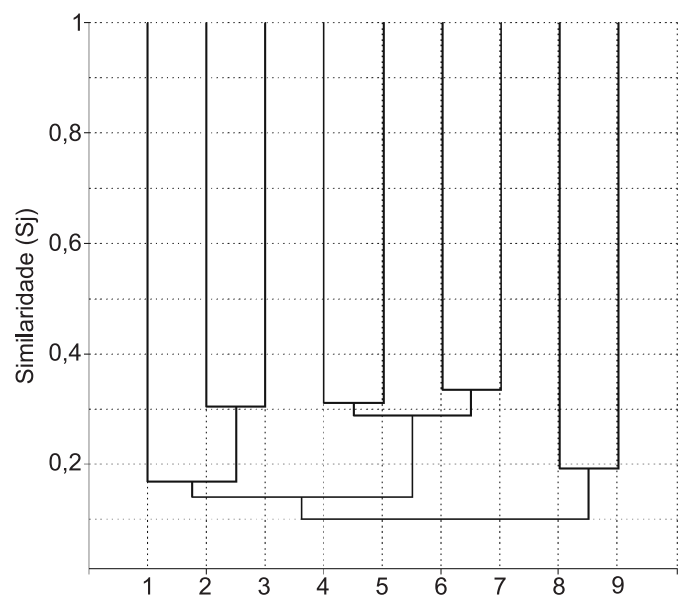

Figura 3 - Dendrograma da análise de agrupamento (UPGMA) entre o componente epifítico vascular de diversas áreas do Sudeste e Sul do Brasil sob domínio de Floresta Estacional (1 = Marcelino Ramos, RS (Rogalski \& Zanin 2003); 2 = PEVR Fênix, PR (Borgo et al. 2002); 3 = Parque Nacional do Iguaçú, PR (Cervi \& Borgo 2007); 4 = Jaboticabal, SP (Pinto et al. 1995); 5 = Alto Rio Paraná, PR (Tomazini 2003); 6 = Estação Ecológica Caetetus, SP (Breier 2005); 7 = Parque do Ingá, PR (este estudo); 8 = Montenegro/Triunfo, RS (Aguiar et al. 1981); $9=$ C.U.A.S.O. São Paulo, SP (Dislich \& Mantovani 1998)). 
possibilitam a ocupação por espécies similares. Embora o PEVR Fênix (354ha) e o Parque do Ingá (47,3ha) estejam situados geograficamente mais próximos (cerca de $50 \mathrm{~km}$ ), apresentam baixa similaridade florística, provavelmente devido à menor área do Parque do Ingá e ao melhor estado de conservação do PEVR Fênix (Borgo et al. 2002).

\section{Agradecimentos}

As autoras agradecem o auxílio prestado, durante as coletas, por Ângela Maria Marques Sanches, do programa de pós-graduação em Ecologia de Ambientes Aquáticos Continentais/Nupélia-UEM e Francisco Calixto, funcionário do Parque Ecológico/UEM; e à bióloga Érica Duarte pela revisão do abstract.

\section{REFERÊNCIAS BIBLIOGRÁFICAS}

Aguiar, L. W.; Citadini-Zanette, V.; Martau, L. \& Backes, A. 1981. Composição florística de epífitos vasculares numa área localizada nos municípios de Montenegro e Triunfo, Rio Grande do Sul, Brasil. Iheringia Serie Botânica 28: 55-93.

Anjos, I. B.; Martins, M. L. O. F. \& Nery, J. T. 2001. Estudo da precipitação pluviométrica e balanço hídrico em Maringá. Boletim de Geografia 19(1): 115-128.

APG II. 2003. An update of the Angiosperm Phylogeny Group classification for the orders and families of flowering plants: APG II. Botanical Journal of the Linnean Society 141: 399-436.

Barthlott, W.; Schmit-Neuerburg, V.; Nieder, J. \& Engwald, S. 2001. Diversity and abundance of vascular epiphytes: a comparison of secondary vegetation and primary montane rain forest in the Venezuelan Andes. Plant Ecology 152: 145-156.

Benzing, D. H. 1990. Vascular epiphytes-General biology and related biota. Cambridge University Press, Cambridge, 354p.

Bigarella, J. J. \& Mazuchowski, J. Z. 1985. Visão integrada da problemática da erosão. In: Livro guia: III Simpósio Nacional de Controle da Erosão, Maringá - PR. ABGE - Associação Brasileira de Geologia e Engenharia, ADEAM Associação de Defesa e Educação Ambiental, Curitiba, 332p.

Borgo, M. \& Silva, S. M. 2003. Epífitos vasculares em fragmentos de Floresta Ombrófila Mista, Curitiba, Paraná, Brasil. Revista Brasileira de Botânica 26(3): 391-401.

; Silva, S. M. \& Petean, M. P. 2002. Epífitos vasculares em um remanescente de Floresta Estacional Semidecidual, município de Fênix, PR, Brasil. Acta Biologica Leopoldensia 24(2): 121-130.

Breier, T. B. 1999. Florística e ecologia de epífitos vasculares em uma floresta costeira do Sul do Brasil. Porto Alegre. Dissertação Mestrado. Universidade Federal do Rio Grande do Sul, 83p. 2005. O epifitismo vascular em florestas do Sudeste do Brasil. Campinas. Tese de Doutorado. Universidade Estadual de Campinas, 139p.

Cervi, A. C.; Acra, L. A.; Rodrigues, L.; Train, S.; Ivanchechen, S. L. \& Moreira, A. L. O. R. 1988. Contribuição ao conhecimento das epífitas (exclusive Bromeliaceae) de uma floresta de Araucária do Primeiro Planalto Paranaense. Ínsula 18: 75-82.

\& Borgo, M. 2007. Epífitos vasculares no Parque Nacional do Iguaçu, Paraná (Brasil). Levantamento preliminar. Fontqueria 55(51): 415-422.

Der, J. P. \& Nickrent, D. L. 2008. A molecular phylogeny of Santalaceae (Santalales). Systematic Botany 33: 107-116.

Dislich, R. \& Mantovani, W. 1998. A flora de epífitas vasculares da Reserva da Cidade Universitária 'Armando de Salles Oliveira' São Paulo, Brasil. Boletim de Botânica da Universidade de São Paulo 17: 61-83.

Dittrich, V. A. O.; Kozera, C. \& MenezesSilva, S. 1999. Levantamento florístico dos epífitos vasculares do Parque Barigüí, Curitiba, Paraná, Brasil. Iheringia Serie Botânica 52: 11-22. 
Gentry, A. H. \& Dodson, C. H. 1987a. Contribution of nontrees to species richness of a tropical rainforest. Biotropica 19(2): 149-156.

\& Dodson, C. H. 1987b. Diversity and biogeography of neotropical vascular epiphytes. Annals of Missouri Botanical Garden 74:205-233.

Giongo, C. \& Waechter, J. L. 2004. Composição florística e estrutura comunitária de epífitos vasculares em uma floresta de galeria Depressão Central do Rio Grande do Sul. Revista Brasileira de Botânica 27(3): 563-572.

Gonçalves, C. N. \& Waechter, J. L. 2003. Aspectos florísticos e ecológicos de epífitos vasculares sobre figueiras isoladas no norte da planície costeira do Rio Grande do Sul. Acta Botanica Brasilica 17(1): 89-100.

Hammer, Ö.; Harper, D. A. T.; \& Ryan, P. D. 2001. PAST: Paleontological statistics software package for education and data analysis. Paleontologia Electronica 4(1): 9.

Hietz, P. 1997. Diversity and conservation of epiphytes in a changing environment. International Conference on Biodiversity and Bioresources: conservation and utilization. Pp. 23-27. Disponível em: http:/ /www.iupac.org/symposia/proceedings/ phuket97/hietz.html.

Hietz-Seifert, U.; Hietz, P. \& Guevara, S. 1996. Epiphyte vegetation and diversity on remmant trees after forest clearance in southern Veracruz. Biological Conservation 75: 103-111.

Kersten, R. A. \& Silva, S. M. 2001. Composição florística e estrutura do componente epifítico vascular em floresta da planície litorânea na Ilha do Mel, Paraná, Brasil. Revista Brasileira de Botânica 24(2): 213-226.

2002. Florística e estrutura do componente epifítico vascular em floresta ombrófila mista aluvial do rio Barigüi, Paraná, Brasil. Revista Brasileira de Botânica 25(3): 259-267.
Lugo, A. E. \& Scatena, F. N. 1992. Epiphytes and climate change research in the Caribbean: a proposal. Selbyana 13: 123-130.

Madison, M. 1977. Vascular epiphytes: their systematic occurrence and salient features. Selbyana 5(2): 207-213.

Margalef, R. 1958. Information theory in Ecology. Genetic Systematic 3: 36-71.

Nadkarni, N. M. 1985. Epiphyte biomass and nutrient capital of a neotropical elfin forest. Biotropica 16(4): 249-256. 1988. Tropical rainforest ecology from a canopy perspective. In: Almeida, F. \& Pringle, C. M. (eds.). Tropical rainforests: diversity and conservation. San Francisco, California Academy of Science and Pacific Division. American Association for the Advancement of Science, 306p.

1992. The conservation of epiphytes and their habitat: summary of a discussion at the international symposium on the biology and conservation of epiphytes. Selbyana 13: 140-142.

Nkongmeneck, B. A.; Lowman, M. D. \& Atwood, J. T. 2002. Epiphyte diversity in primary and fragmented forests of Cameroon, Central Africa: a preliminary survey. Selbyana 23(1): 121-130.

Odum, E. P. 1988. Ecologia. Ed. Guanabara, Rio de Janeiro, 434p.

Partomihardjo, T. 2003. Colonisation of orchids on the Krakatau Islands. Telopea 10(1): 299-310.

Pinto, A. C. R.; Demattê, M. E. S. P. \& Pavani, M. C. M. D. 1995. Composição florística de epífitas (Magnoliophyta) em fragmento de floresta no município de Jaboticabal, SP, Brasil. Científica 23(2): 283-289.

Prefeitura Municipal de Maringá. 1994. Plano de Manejo: Parque do Ingá. Prefeitura Municipal de Maringá, Maringá, 74p.

Richter, M. 1991. Methoden der Klimaindikation durch pflanzenmorphologische Merkmale in den Kordilleren der Neotropis. Die Erde 122: 267-289. 
Rogalski, J. M. \& Zanin, E. M. 2003. Composição florística de epífitos vasculares no estreito de Augusto César, Floresta Estacional Decidual do Rio Uruguai, RS, Brasil. Revista Brasileira de Botânica 26(4): 551-556.

Tomazini, V. 2003. Epífitas vasculares em vegetação ripária da planície alagável do alto Rio Paraná, Brasil. Dissertação Mestrado. Universidade Estadual de Maringá, Maringá, 85p.

Tryon, R. M. 1970. Development and evolution of Fern Floras of Oceanic Islands. Biotropica 2(2): 76-84. \& Tryon, A. 1982. Ferns and Allied Plants. Springer, New York, 857p.

Turner, I. M.; Tan, H. T. W.; Wee, Y. C.; Ibrahin, A. B.; Chew, P. T. \& Corlett, R.
T. 1994. A study of plant species extinction in Singapore: lessons for the conservation of tropical biodiversity. Conservation Biology 8(3): 705-712.

Waechter, J. L. 1986. Epífitos vasculares da mata paludosa do Faxinal, Torres, Rio Grande do Sul, Brasil. Iheringia Serie Botânica 34: 39-49.

1992. O epifitismo vascular na planície costeira do Rio Grande do Sul. São Paulo. Tese de Doutorado. Universidade Federal de São Carlos, 162p.

1998. Epifitismo vascular em uma floresta de restinga do Brasil subtropical. Revista Ciência e Natura 20: 43-66.

Zotz, G. 1995. How fast does an epiphyte grow? Selbyana 16: 150-154. 